\title{
Exploring Adult Mental Health in Minority Ethnic Groups in the Royal Borough of Greenwich: Implications of Partnership Working
}

\author{
Andrea Valentine ${ }^{1}$, Nadia Maddy ${ }^{1}$, Adeniyi Adeboye ${ }^{2}$, Fahad Algahtani² $^{2}$ Aderonke Jegede $^{3}$ \\ ${ }^{1}$ UKCBC/Bath Spa University Programme, London, UK \\ ${ }^{2}$ College of Public Health and Health Informatics, University of Hail, Hail, KSA \\ ${ }^{3}$ Sunny Downstate Health Sciences University, New York, USA \\ Email: andreavalentine00@gmail.com,Nmaddy@ukcbc.ac.uk, adeboye05@yahoo.co.uk,dr.algahtani@gmail.com, \\ ronkejegede@gmail.com
}

How to cite this paper: Valentine, A., Maddy, N., Adeboye, A., Algahtani, F. and Jegede, A. (2019) Exploring Adult Mental Health in Minority Ethnic Groups in the Royal Borough of Greenwich: Implications of Partnership Working. Open Journal of Social Sciences, 7, 238-248.

https://doi.org/10.4236/jss.2019.79018

Received: August 27, 2019

Accepted: September 21, 2019

Published: September 24, 2019

Copyright $\odot 2019$ by author(s) and Scientific Research Publishing Inc. This work is licensed under the Creative Commons Attribution International License (CC BY 4.0).

http://creativecommons.org/licenses/by/4.0/

\section{(c) (i) Open Access}

\begin{abstract}
This study examines the perception of the relationship between mental health and ethnicity and looks at partnership working within the adult mental health services in the Royal Borough of Greenwich. To explore these issues, semi-structured one-to-one interviews were conducted with gatekeepers. Secondary data of 212 service users were also collected to further investigate the relationship between ethnicity and mental health. Both qualitative and quantitative methods were used to carry out this research. Findings from this study revealed that people's perceptions of the relationship between mental health and ethnicity are often biased by society's opinion or their own ethnic heritage, and consequently these perceptions do not correspond with statistical data. Further findings also reveal that providers would need additional information/training to understand partnership working. Findings also highlight the importance of psychoeducation of the wider public in order to reduce the severity of mental health problems among minority ethnic groups, as it was identified by the interviewed gatekeepers that cultural issues (mental health is taboo and/or stigmatised) can hinder individuals from accessing the right services at the right time. This is an explorative study; therefore, further rigorous research approach is needed to establish association between mental health and ethnicity.
\end{abstract}

\section{Keywords}

Mental Health, Ethnicity, Partnership Working 


\section{Introduction}

The first Director-General of the World Health Organisation, Dr Brock Chisholm, once said that "without mental health there can be no true physical health". Despite this acknowledgement of the importance of mental health, the issue remains a growing public health concern. Mental health problems are prevalent not just in the UK but around the world [1].

\subsection{Mental Health and Ethnicity}

Different ethnic groups have different experiences and rates of mental health problems, which reflects their cultural and socioeconomic context and access to culturally appropriate treatment. According to the Mental Health Foundation (2018), studies have shown that minority ethnic groups are more likely to be diagnosed with a mental health problem, be admitted to hospital and experience poor outcomes from treatment [2]. In addition, studies conducted by Wessely et al. (1991), Van Os et al. (1996), King et al. (1994) and Bhugra et al. (1997) showed that minority groups are also more likely to disengage from mental health services, leading to social exclusion and deterioration in their mental health [3]. These ethnic differences in rates of mental health may be explained by several factors, including poverty and racial discrimination. There is also a high propensity for these ethnic differences to be attributed to poor mental health services. In addition, ethnic minorities may find mental services inaccessible, especially when compared to non-minority ethnic groups. While there are mental health services available, they may not be tailored meaningfully to meet ethnic minority mental health needs in a culturally sensitive way. Mental health problems are also likely to go unreported, as some ethnic groups are reluctant to engage with mental health services due to the potency of the stigma surrounding mental illness, thus creating preventable morbidities and mortalities. Over- or misdiagnosis is also likely to occur among ethnic minority groups who mostly are not native English speakers [3].

\subsection{Partnership Working}

The scope of activities that are required to provide holistic support services to people with mental health problems-especially people from ethnic minority groups-means that a single organisation would find it difficult to succeed. However, through partnership working it is possible to reach a greater number of people with better services. Partnership working in health and social care brings together separate organisations so that they can benefit from pooled expertise and resources as well as power sharing. The goal of partnership working is to enhance the efficiency and quality of service provision [4].

Mental health problems can cause a considerable burden to sufferers, carers and society. An increased rate of schizophrenia has been consistently reported among people of African and African-Caribbean origin and less consistently among those of South-Asian origin [5]. 
It is generally inferred that partnership working produces better results, such as a wider range of services that better meet the service users' needs, and is more beneficial to professionals, but there is very little evidence to support these hypotheses. However, there are potential benefits of the involvement of the voluntary sector in mental For example, it can: complement the statutory mental health sector; offer practical help and financial advice regarding housing and welfare benefits; play an important advocacy role to improve mental health services; and combat social exclusion by providing local opportunities for employment, education, social networks and leisure. The community sector is recognised for its potential to engage hard-to-engage people. It adds value to the statutory mental health services through its user-focused approach and user-led services, and it is more trusted by service users due to its independence [6].

People with mental health problems and their carers are among the most socially excluded and disadvantaged groups in society, which means they have limited opportunities to engage in employment, education, leisure and social activities [6] [7]. They often require support beyond healthcare, such as with the financial and practical aspects of daily life, benefits advice and employment support. To address these complex social and mental health needs necessitates a multi-agency approach [8].

\subsection{What Is Partnership Working?}

There are several definitions to partnership working. According to Jo Tunnard, former associate director of Child Poverty Action Group, the essence of partnership is sharing. Each partner is seen as having something to contribute, decisions are made jointly, and roles are not only respected but are also backed by legal and moral rights. Meanwhile, Blackburn Anglican, a Lancashire church with a vision of changing communities through partnership working, says partnerships can be formed between individuals, agencies or organisations with a shared interest. There is usually an overarching purpose for partners to work together [4].

Partnership working between the NHS, voluntary sector and social services is essential to provide mental health service users with a wide range of effective services to promote their recovery. Despite this, there is a lack of research-based evidence to demonstrate the effectiveness of partnership working in the provision of integrated mental health services [6].

\subsection{Policy Context}

Delivering health and social care services by working in partnership with statutory agencies has been a political priority for over two decades. The government's commitment to support the voluntary sector's role in delivering public services is demonstrated in the various policy documents, such as Developing Partnerships in Mental Health Green Paper 1997, which details the role of the voluntary sector in partnership with community mental health teams (CMHTs) 
in providing housing and employment services. The National Compact sets out a framework to improve partnership working between government and the voluntary sector. The Compact was renewed in 2010 between the UK government and third sector organizations [9]. Making Partnership Work for Patients, Carers and Service Users (2004) is a strategic agreement between the Department of Health, the NGOs and the Voluntary and Community Sector to develop innovative ways of partnership working [10]. Finally, the 2002 Cross-Cutting Review explored the ways central and local government could work in partnership with the voluntary sector to deliver high-quality services as well as identifying barriers preventing the involvement of the voluntary sector. This review led to increased public expenditure through the Future builders and Change Up initiatives [11].

\section{Main Body}

The aims and objectives of this research are to explore the frequency and severity of mental illness in minority ethnic groups in the Royal Borough of Greenwich. It also aims to: examine the impact of partnership working on adult mental health services in the Royal Borough of Greenwich; identify the number of possible barriers preventing the implementation of partnership working within the borough; and recommend possible solutions to improve partnership working within the adult mental health services in the borough.

This research broadly investigates the following:

1) What are the perceptions of mental health in minority groups with regard to partnership working?

2) What are the potentiating factors in partnership working with regard to the mental health of minority groups?

This study hypothesises that mental illness is more common among people from minority ethnic groups. It also hypothesises that the legally required partnership working is known to service providers, but not to service users because of its poor implementation.

This study looks at the mental health of ethnic minority groups and partnership working within the adult mental health services in the Royal Borough of Greenwich. Therefore, it must be acknowledged that this was a small-scale, mixed-method study, which should not be used to make generalisations.

\subsection{Findings from Interviews}

The main themes that emerged from the interviews with gatekeepers are:

1) Perception of the occurrence of mental health problems among minority ethnic groups

2) The most common contributing factors to mental ill health among minority ethnic groups

3) Understanding of partnership working and the improvements needed to make it work better

4) Barriers of partnership working 
5) Understanding what improvements are needed to the adult mental health services for minority ethnic groups in the Royal Borough of Greenwich.

\subsubsection{Perception of the Occurrence of Mental Health Problems among Minority Ethnic Groups}

Most gatekeepers had the same perception, namely that the number of people from minority ethnic backgrounds represented within the mental health services are disproportionately high within the Royal Borough of Greenwich (RBG). It also emerged that people from minority ethnic backgrounds are more often sectioned under the Mental Health Act 1983, 2007 (MHA) and hospitalised than other ethnicities. As one interviewee said: "My perception is that it's quite high if you compare it to the number of people from ethnic minorities from the borough."

However, when looking at the secondary data, it shows that the number of people from White British ethnic background is higher than the ethnic minorities.

\subsubsection{The Most Common Contributing Factors to Mental Ill Health within Minority Ethnic Groups}

It was felt by the interviewed gatekeepers that the most common contributing factors were drug use, poverty, family breakdown, cultural and religious beliefs. One interviewee listed the factors as: "substance misuse as well as people coming into service because of high poverty, lack of social support, lack of employment and because we are serving quite a high number of people with low demographic index".

\subsubsection{Understanding Partnership Working and the Improvements Needed to Make It Work Better}

All interviewed gatekeepers agreed that partnership working means working together for a common goal. They said that partnership working is essential within the adult mental health services. Most gatekeepers agreed that to improve partnership working, all partners need to have a clear understanding of each partner's roles and responsibilities, as without this a partnership will become unequal and ultimately will not work. One interviewee stated: "I would define partnership working as working for a common goal. I would define it as understanding what the other parties are bringing to the partnership. I think there has to be a common goal." Concerning improvements that could be made to partnership working, another interviewee noted: "It can be improved with clearer responsibilities and accountability for the partners doing their different roles."

\subsubsection{Barriers to Partnership Working}

Most gatekeepers felt that a lack of effective communication is one of the main barriers to partnership working, together with a lack of resources and the fact that different providers might have different governing bodies and therefore different priorities. One of the interviewees noted: "Communication is a big barrier and hurdle to get over." 


\subsubsection{Improvement Needs for Adult Mental Health Services for Minority Ethnic Groups in RBG}

Some gatekeepers felt that there is no discrimination in the services provided; they felt that it is substandard regardless of the service users' ethnicities.

Others said that services need to be improved mainly through psychoeducation, to allow minority ethnic groups to have a better understanding of mental health problems and to access services at the right time to get the right treatment. One interviewee responded: “I don't see a different level of service being paid toward minorities, I see the same. I am going to say a substandard service is given to all clients regardless of their ethnicity."

\subsection{Findings from Secondary Data}

Secondary data of 212 service users were collected and analysed regarding ethnicity, mental health diagnosis and gender. The sample contained 129 (60.85\%) males and 83 (39.15\%) females. Of the 129 males, 66 were from a minority ethnic background, compared with 30 of the 83 females (Table 1 ).

- Paranoid Schizophrenia $40.3 \%$ of white males and 33.9\% of white females in the sample were diagnosed with this condition, compared with $38.62 \%$ of ethnic minority males and $55.5 \%$ of ethnic minority females (Table 2 and Table 3).

- Depression $19.4 \%$ of white males and $35.7 \%$ of white females had this diagnosis, compared with only $3.5 \%$ of minority males and $7.4 \%$ of minority females (Table 2 and Table 3 ).

- Schizophrenia $12.5 \%$ of white males were diagnosed with this illness, compared with only $3.6 \%$ of white females. In contrast, $29.8 \%$ of minority males and $11.1 \%$ minority females had the same diagnosis (Table 2 and Table 3 ).

- Schizoaffective Disorder Only $5.5 \%$ of white males and $10.7 \%$ of white females had this diagnosis, compared with $8.7 \%$ of minority males and $11.1 \%$ of minority females (Table 2 and Table 3 ).

- Psychosis 6.9\% of white males and no white females had this diagnosis, compared with $7 \%$ of minority males and $7.4 \%$ minority females (Table 2 and Table 3).

- Bipolar Affective Disorder $5.8 \%$ of white males and $7.1 \%$ of white females had this diagnosis, compared with $7 \%$ of minority males and only $3.7 \%$ of minority females (Table 2 and Table 3).

- Anxiety Of the white males in the sample, $12.5 \%$ had this diagnosis, whilst $23.3 \%$ of white females had it. In comparison, the figure for minority males was only $1.75 \%$ and for minority females, $3.7 \%$ (Table 2 and Table 3 ).

- Personality Disorder This diagnosis affected $15.3 \%$ of white males, whilst the figure for white females was more than double, at $32.15 \%$. None of the minority males in this sample had the diagnosis, compared with $11.1 \%$ of minority females (Table 2 and Table 3 ).

- Organic Delusional Disorders These were only found in white females (3.6\%) in this sample. 
- Korsakoff s Syndrome This was only found in white males (4.2\%).

- Obsessive-Compulsive Disorder $2.8 \%$ of white males and $1.8 \%$ of white females had this diagnosis, compared with $1.7 \%$ of minority males and no minority females (Table 2 and Table 3 ).

- Mental and Behavioural Disorders No minority females were diagnosed with these disorders, but $1.7 \%$ of minority males, $1.4 \%$ of white males and $5.35 \%$ of white females had this diagnosis (Table 2 and Table 3 ).

Table 1. Sample based on gender and ethnicity.

\begin{tabular}{cccc}
\hline Ethnicity & Male & Female & Total \\
\hline White British & 63 & 53 & 116 \\
Ethnic Minorities & 66 & 30 & 96 \\
Total & 129 & 83 & 212 \\
\hline
\end{tabular}

Table 2. Sample based on diagnosis and ethnicity.

\begin{tabular}{ccc}
\hline Diagnosis & Ethnic Minorities & White British \\
\hline Obsessive Compulsive Disorder & 1 & 34 \\
Paranoid Schizophrenia & 41 & 30 \\
Depression & 8 & 10 \\
Schizophrenia & 21 & 7 \\
Schizoaffective Disorder & 11 & 7 \\
Psychosis & 4 & 8 \\
Bipolar Affective Disorder & 5 & 19 \\
Anxiety & 9 & 28 \\
Personality Disorders & 4 & 2 \\
Organic Delusional Disorder & 0 & 3 \\
Korsakoffs Syndrome & 0 & 4
\end{tabular}

Table 3. Sample based on diagnosis and gender.

\begin{tabular}{ccc}
\hline Diagnosis & Male & Female \\
\hline Obsessive Compulsive Disorder & 3 & 1 \\
Paranoid Schizophrenia & 51 & 34 \\
Depression & 16 & 22 \\
Schizophrenia & 26 & 5 \\
Schizoaffective Disorder & 9 & 9 \\
Psychosis & 9 & 2 \\
Bipolar Affective Disorder & 8 & 5 \\
Anxiety & 9 & 14 \\
Personality Disorders & 11 & 21 \\
Organic Delusional Disorder & 0 & 2 \\
Korsakoff's Syndrome & 3 & 0
\end{tabular}


One hypothesis of this study was that mental illness is more common among people from minority ethnic groups than among the white British population, both in frequency and severity. However, this study finds that overall, the frequency of mental ill health is similar when looking at the more complicated and/or serious mental health diagnoses, such as paranoid schizophrenia (40.3\% of white males were affected, compared to $38.62 \%$ of minority males); psychosis (6.9\% of white males, compared to $7 \%$ of minority males); schizoaffective disorder ( $10.7 \%$ of white females, compared to $11.1 \%$ of minority females). However, only $12.5 \%$ of white males had schizophrenia, compared to $29.8 \%$ minority males and only $3.6 \%$ of white females, compared to $11.1 \%$ minority females.

On the other hand, white people in the study were more likely to suffer from the "less severe" mental health problems: depression affected $19.4 \%$ of white males, compared to $3.5 \%$ minority males and $35.7 \%$ white females, compared to only $7.4 \%$ minority females; anxiety affected $12.5 \%$ of white males and only $1.75 \%$ of minority males and $23.3 \%$ of white females, compared to $3.7 \%$ of minority females; personality disorders affected $15.3 \%$ of white males, compared to $0 \%$ of minority males and $32.5 \%$ of white females compared to $11.1 \%$ of minority females. There were some diagnoses, such as organic delusional disorder and Korsakoff s syndrome, which affected only white people.

\subsection{Perceptions of the Connection between Ethnicity and Mental Health}

Harrison et al. (1998) stated that minority ethnic groups were more likely than others to be diagnosed with a mental health problem, and this seems to be the perception of the gatekeepers interviewed for this study as well. However, looking at the data collected, it appears that out of the 212 service users, only 84 (39.6\%) were from minority ethnic backgrounds. This is consistent with the Royal Borough of Greenwich's ethnic profile, which states that the population is $60 \%$ white and $40 \%$ minority ethnic groups [12].

One hypothesis of this study was that mental illness is more common among people from minority ethnic groups than among the white British population, both in frequency and severity. However, this study finds that overall, the frequency of mental ill health is similar when looking at the more complicated and/or serious mental health diagnoses, such as paranoid schizophrenia (40.3\% of white males were affected, compared to $38.62 \%$ of minority males); psychosis (6.9\% of white males, compared to $7 \%$ of minority males); schizoaffective disorder ( $10.7 \%$ of white females, compared to $11.1 \%$ of minority females). However, only $12.5 \%$ of white males had schizophrenia, compared to $29.8 \%$ minority males and only $3.6 \%$ of white females, compared to $11.1 \%$ minority females.

On the other hand, white people in the study were more likely to suffer from the "less severe" mental health problems: depression affected $19.4 \%$ of white males, compared to $3.5 \%$ minority males, and $35.7 \%$ white females, compared to only $7.4 \%$ minority females; anxiety affected $12.5 \%$ of white males and only $1.75 \%$ of minority males, and $23.3 \%$ of white females, compared to $3.7 \%$ of mi- 
nority females; personality disorders affected $15.3 \%$ of white males, compared to $0 \%$ of minority males, and $32.5 \%$ of white females, compared to $11.1 \%$ of minority females. There were some diagnoses, such as organic delusional disorder and Korsakoff's syndrome, which affected only white people.

It appears that the original hypothesis of mental illness being more common among minority ethnic groups, both in frequency and severity, is not verifiable in this study, as the data shows that the more severe mental health problems were almost evenly distributed between ethnic minorities and white ethnicities with the exception of schizophrenia, which was more frequent in minority ethnic groups. However, when looking at the "less severe" mental health diagnoses, this study shows that people from white ethnic background are more frequently diagnosed than ethnic minority groups, especially when taking gender into consideration.

\subsection{Partnership Working}

This study notes that there is a general understanding of the ethos of partnership working, which is working together for a common goal. The interviewed professionals also felt that partnership working is essential within the adult mental health services due to the complexity of mental ill health.

This study hypothesised that, despite having a formal partnership working agreement, the effects of the agreement are not felt by the service users. This research found this hypothesis to be true. There is a section 75 agreement between providers and the Royal Borough of Greenwich, but the gatekeepers interviewed felt that service users did not benefit from this. This study found that communication was one of the main barriers to effective partnership working, together with a lack of resources. Having different providers with different priorities also makes it difficult to work together effectively.

This study also finds that services do not necessarily need to be different for people from minority ethnic backgrounds. However, there is a need to increase cultural awareness together with psychoeducation to enable better services to be provided for minorities. Psychoeducation should help to give people from minority ethnic background a better understanding of how and when to access services and to reduce the stigma that comes with having a mental health diagnosis.

\section{Conclusions and Recommendations}

One of the findings of this study is that whilst partnership works on a policy level, in practice partners often do not understand each other and their own roles and responsibilities within the partnership, causing partnerships to become unequal and eventually break down. Therefore, it is essential to facilitate additional training for providers to improve partnership working and lower barriers.

This study also found that regular meetings between providers to share good practice could enable closer partnership working.

There is a need to further involve communities and voluntary sector organiza- 
tions to deliver high quality services for people with mental health problems. This could have several benefits, such as using the experience and expertise of local people and reaching out to communities, which could prove vital in reducing stigma and enabling access to services for those who have not been able to access them so far due to cultural and/or religious beliefs.

This study recommends widespread psychoeducation for everyone about mental illness and a more extensive use of cross-cultural psychiatric practices.

Finally, there is a need to investigate the relationship between mental health and ethnicity further, as not enough wide-ranging studies have been conducted to uncover the true extent of more serious mental health problems among ethnic minorities, and the extent to which these problems are under-reported due to stigma. Once this relationship is better understood, then there is a need to find solutions to these problems.

\section{Acknowledgements}

The authors would like to thank the directors and management team of Bridge Support, the commissioners for Royal Borough of Greenwich Clinical Commissioning Group and the management of the Greenwich Home Treatment Team, who offered to be interviewed and provided insightful detailed information that helped in powering the research output.

\section{Conflicts of Interest}

The authors declare no conflicts of interest regarding the publication of this paper.

\section{References}

[1] Kolappa, K., Henderson, D. and Kishore, S. (2013) No Physical Health without Mental Health: Lessons Unlearned? Bulletin of the World Health Organization, 91, 3-3A. https://www.who.int/bulletin/volumes/91/1/12-115063/en https://doi.org/10.2471/BLT.12.115063

[2] Harrison, G., Owens, D., Holton, A., Neilson, D. and Boot, D. (1988) A Prospective Study of Severe Mental Disorder in Afro-Caribbean Patients. Psychological Medicine, 18, 643. https://doi.org/10.1017/S0033291700008321

[3] Gary, F. (2005) Stigma: Barrier to Mental Health Care among Ethnic Minorities. Issues in Mental Health Nursing, 26, 979-999. https://doi.org/10.1080/01612840500280638 https://www.tandfonline.com/doi/abs/10.1080/01612840500280638

[4] Sheehy, R. (2017) Partnership Working in Health and Social Care: The Bridge Perspective.

https://www.bridgesupport.org/blog/partnership-working-health-social-care/

[5] Boydell, J., van Os, J., McKenzie, K., Allardyce, J., Goel, R., McCreadie, R. and Murray, R. (2001) Incidence of Schizophrenia in Ethnic Minorities in London: Ecological Study into Interactions with Environment. British Medical Journal, 323, 1336-1336. https://doi.org/10.1136/bmj.323.7325.1336

[6] Tait, L. and Shah, S. (2007) Partnership Working: A Policy with Promise for Mental 
Healthcare. Advances in Psychiatric Treatment, 13, 261-271.

https://doi.org/10.1192/apt.bp.106.003178

[7] ODPM (2004) Mental Health and Social Exclusion Social Exclusion Unit Report Summary.

http://www.nfao.org/Useful_Websites/MH_Social_Exclusion_report_summary.pdf

[8] Morgan, S. (2000) Clinical Risk Management: A Clinical Tool and Practitioner Manual. Sainsbury Centre for Mental Health, London.

[9] National Audit Office (2018) The Compact.

https://www.nao.org.uk/successful-commissioning/general-principles/the-compact

[10] DoH (2004) Making Partnership Work for Patients, Carers and Service Users: A Strategic Agreement between the Department of Health, NHS and Voluntary and Community Sector. https://www.bipsolutions.com/docstore/pdf/8297.pdf

[11] DoH (2002) Tackling Health Inequalities-2002 Cross-Cutting Review. http://webarchive.nationalarchives.gov.uk/20110321235115/http://www.dh.gov.uk/e n/Publicationsandstatistics/Publications/PublicationsPolicyAndGuidance/DH_4098 $\underline{280}$

[12] Divajeva, D., Owusu-Agyemang, K. and Wood, A. (2016) Joint Strategic Needs Assessment: Greenwich Population Profile.

http://www.greenwichjsna.org/app/uploads/2015/08/Demography_JSNA-1.pdf 